\title{
Complementary and alternative medicine use by patients with inflammatory bowel disease: An Internet survey
}

\author{
Robert J Hilsden MD MSc FRCPC ${ }^{1}$, Jon B Meddings MD FRCPC ${ }^{2}$, Marja J Verhoef $\mathrm{PhD}^{1}$
}

RJ Hilsden, JB Meddings, MJ Verhoef. Complementary and alternative medicine use by patients with inflammatory bowel disease: An Internet survey. Can J Gastroenterol 1999;13(4): 327-332.

OBJECTIVES: To determine the degree and determinants of the use of complementary and alternative medicine (CAM) by patients with inflammatory bowel disease (IBD) with the use of the Internet and to compare the results with those found by using a similar survey in patients attending gastroenterology clinics in Calgary, Alberta.

SUBJECTS AND METHODS: A cross-sectional survey of 263 patients with IBD with the use of a World Wide Webbased, structured questionnaire was conducted.

RESULTS: Complementary therapies had been used by $46 \%$ of patients in the previous two years. Current use was reported by $34 \%$. Vitamins, herbal products and natural health practices were the most commonly reported therapies. Side effects and lack of effectiveness of standard therapies were the most commonly cited reasons for seeking complementary medicine. However, despite this, respondents who had previously received surgery, or intravenous or oral steroids were less likely to be current CAM users. Important differences between the determinants of and reasons for CAM use in the present study and those of a similar study of IBD patients in a local tertiary care setting were noted.

CONCLUSIONS: Complementary medicine use is common in patients with IBD. Differences in the determinants of and reasons for CAM use noted between the present Internet sample and a gastroenterology clinic sample suggest that conclusions from the present study and from previous studies based only on clinic samples provide a limited view of CAM use by people with IBD. More comprehensive assessments are needed.

Key Words: Alternative medicine; Complementary medicine; Health behaviours; Inflammatory bowel disease; Internet; Self treatment

Médecines douces et alternatives chez les patients atteints d'une maladie inflammatoire de l'intestin : sondage par Internet

OBJECTIFS : Mesurer le recours aux médecines douces ou alternatives et les motifs invoqués par les patients atteints de maladie inflammatoire de l'intestin par le biais de l'Internet et comparaison des résultats avec ceux d'un sondage similaire administré à des patients participant à des cliniques de gastroentérologie à Calgary, en Alberta.

SUJETS ET MÉTHODES : Enquête transversale sur 263 patients atteints de MII par le biais de questionnaires structurés diffusés sur le voir page suivante

This project was funded by a grant from the Foothills Hospital Foundation (Penser Fund)

Departments of ${ }^{1}$ Community Health Sciences and ${ }^{2}$ Medicine, University of Calgary, Calgary, Alberta

Correspondence: Dr Robert Hilsden, Department of Community Health Sciences, 3330 Hospital Drive NW, Calgary, Alberta

T2N 4N1. Telephone 403-220-6536, fax 403-270-7287, e-mail rhilsden@acs.ucalgary.ca

Received for publication June 16, 1998. Accepted October 21, 1998 
Web.

RÉSULTATS : Les médecines douces ont été utilisés par $46 \%$ des patients au cours des deux années précédentes. L'emploi actuel a été signalé par $34 \%$. Les vitamines, les herbes médicinales et les approches dites «naturelles » ont été les modalités thérapeutiques les plus souvent mentionnées. Les effets secondaires et l'inefficacité des traitements classiques ont été les raisons les plus souvent invoquées pour se tourner vers les médecines douces. Par contre, en dépit de cela, les répondants ayant par le passé été traités par chirurgie, par corticostéroïdes intraveineux ou oraux, étaient moins susceptibles d'être des utilisateurs des médecine douce. On a noté d'importantes différences entre les facteurs déterminants et les motifs entourant l'utilisation des médecines douces de l'étude actuelle et d'une étude semblable menée auprès de patients atteints de MII dans le contexte d'un établissement local de soins tertiaires.

CONCLUSIONS : Les patients atteints de MII ont souvent recours aux médecines douces. Les différences, quant aux facteurs déterminant le recours aux médecines douces et les motifs invoqués notés entre l'échantillon Internet actuel et l'échantillon d'une clinique de gastroentérologie donnent à penser que les conclusions de la présente
$\mathrm{C}$ omplementary and alternative medicine (CAM) use is increasing in Western countries. Astin (1) reported that $40 \%$ of American adults had used some form of CAM in the previous year. CAM differs from conventional medicine in many important ways, including beliefs about disease causation, treatment and the nature of the therapeutic relationship between the practitioner and the patient (2). For example, the patient often plays a much more active role in CAM rather than being a passive recipient of therapy as often occurs in conventional medicine. Patients often seek CAM after conventional medicine has failed (3). However, patients may also use CAM because their attitudes and beliefs are more in keeping with those of CAM rather than conventional medicine (1).

The use of CAM by patients with inflammatory bowel disease (IBD) has been the focus of several studies. Smart et al (4) reported in 1986 that only $4 \%$ of patients with Crohn's disease attending an out-patient clinic in The United Kingdom were currently using alternative medicine. Verhoef and Sutherland (5) showed that the proportion of IBD patients consulting a complementary practitioner for the same reason as they saw their gastroenterologist $(15 \%)$ was higher than the proportion $(8 \%)$ for other gastrointestinal patients. In 1996, Moser et al (6) found that $34 \%$ of Austrian IBD patients used alternative therapies. In a recent study, we (7) found that CAM had been used in the previous two years by $51 \%$ of patients attending clinics of university-affiliated gastroenterologists in Calgary, Alberta. Current use was reported by $33 \%$. The most common reasons for using CAM were the side effects and lack of beneficial effect of conventional treatments.

These studies were all limited to patients attending medical clinics, usually at tertiary referral centres. Conclusions from studies of these populations may not hold true for the general IBD population or for different IBD subpopulations. This is because patients attending specialty clinics may differ in important ways from the general IBD population. For example, a clinic population may be sicker and require more intensive treatment and followup. Furthermore, they may be more comfortable relying predominantly on Western medicine approaches to their disease than patients not attending these types of clinics.
Unfortunately, there are no population-based studies of CAM use by patients with IBD. Therefore, the current view of the degree and determinants of CAM use by patients with IBD comes from a single perspective.

It would be problematic in North America to conduct a survey of a more general IBD population because identifying all patients with IBD from which to draw a sample would be difficult. In situations where an ideal study is difficult or not feasible, the use of multiple populations and methods (triangulation) can be used to gain a fuller understanding of a phenomenon. Therefore, to assess the use of CAM either by self-treatment or through a practitioner in a different IBD population, we conducted a survey on the Internet using the same questionnaire as that used in our recent study described above (7). Although we recognized that this population would also not represent the general IBD population, we believed that it would provide a different population with which to compare our findings from our local IBD population. In particular, the Internet population may be more likely to include patients with less severe disease and patients who are more comfortable with alternative approaches to their disease than those in specialty clinics. For these reasons, it may include patients who are less likely to be seen regularly by a gastroenterologist.

It is also important to understand the attitudes and behaviours of this population because patients are increasingly turning to the Internet and to fellow patients on the Internet for information about their disease and its treatments (8).

The specific objectives of the present study were to determine, in patients with IBD using the Internet, the degree of use of CAM, the reasons for seeking CAM and the determinants of CAM use. Additional objectives were to compare the findings in the Internet population with those from our local clinic population and to assess the feasibility of using the Internet to recruit subjects and collect survey data.

\section{SUBJECTS AND METHODS}

The questionnaire used in our survey of local IBD patients was converted into hypertext markup language and made available over the World Wide Web via the University of Calgary GI Research Group website. (The questionnaire 
TABLE 1

Demographic characteristics of the inflammatory bowel disease study population

\begin{tabular}{lccc}
\hline & $\begin{array}{c}\text { Crohn's disease } \\
(\mathbf{n = 1 5 8})\end{array}$ & $\begin{array}{c}\text { Ulcerative } \\
\text { colitis }(\mathbf{n}=\mathbf{9 7})\end{array}$ & $\begin{array}{c}\text { All subjects } \\
(\mathbf{n}=\mathbf{2 6 3})^{*}\end{array}$ \\
\hline Males (\%) & 54 & 47 & 51 \\
$\begin{array}{c}\text { Age, mean years } \\
\quad \text { (range) }\end{array}$ & $36(8-63)$ & $37(6-77)$ & $36(6-77)$ \\
$\begin{array}{c}\text { Education (\%) } \\
\text { Highschool or less }\end{array}$ & $29(19 \%)$ & $12(13 \%)$ & $43(17 \%)$ \\
$\quad \begin{array}{c}\text { At least some } \\
\text { postsecondary }\end{array}$ & $127(81 \%)$ & $84(87 \%)$ & $217(83 \%)$ \\
\hline
\end{tabular}

For some items, the numbers may not add up to the total number of subjects due to missing responses. *Includes eight subjects who did not specify type of inflammatory bowel disease

is available from the authors.) The questionnaire included questions on demographic and disease characteristics, and on current and past use of conventional and complementary medicine. There were several questions about the reasons for seeking CAM. Respondents had the option of providing their e-mail address or remaining anonymous. Unless e-mail addresses were provided in this way, the investigators did not have access to identifying information about individual respondents.

Subjects were recruited in two phases over 12 months. In the first phase (June to August 1996), potential subjects were solicited by placing an announcement several times on Internet IBD newsgroups (eg, alt.support.crohns-colitis) and newsletters (eg, IBDList Digest). In the second phase (September 1996 to May 1997), subjects were not solicited by any active means; however, patients could access the questionnaire through several Internet search engines or if they viewed the GI Research Group homepage. The following text was used to recruit subjects.

We are conducting a study on the beliefs and perspectives of people with inflammatory bowel disease towards the treatment of their disease. In this study we are not only interested in the beliefs about traditional medical therapies (ie, prednisone) but also on complementary or alternative therapies (ie, herbal therapies, homeopathy). We invite you to participate in this study by responding to a few questions.

To examine potential factors associated with the use of CAM, bivariate and multivariate analyses were conducted using Fisher's exact tests, Kruskal-Wallis rank tests and logistic regression. Analysis focused on the examination of the key predictive variables identified in the local IBD population. Odds ratios (ORs) with $95 \%$ CIs were computed to assess the strength of associations. Tests were considered statistically significant at the 0.05 level.

The study was approved by the University of Calgary Conjoint Health Research Ethics Board.
TABLE 2

Disease characteristics and treatment history of the inflammatory bowel disease study population

\begin{tabular}{lccc}
\hline & $\begin{array}{c}\text { Crohn's disease } \\
(\mathbf{n = 1 5 8})\end{array}$ & $\begin{array}{c}\text { Ulcerative } \\
\text { colitis }(\mathbf{n = 9 7 )})\end{array}$ & $\begin{array}{c}\text { All subjects } \\
(\mathbf{n = 2 6 3})^{*}\end{array}$ \\
\hline $\begin{array}{l}\text { Disease activity (\%) } \\
\quad \text { Active }\end{array}$ & $111(71)$ & $65(67)$ & $182(70)$ \\
$\quad$ Inactive & $45(29)$ & $32(33)$ & $79(30)$ \\
$\begin{array}{l}\text { Disease duration, } \\
\quad \text { median years } \\
\text { (range) }\end{array}$ & $7(0.5-42)$ & $7(0.25-32)$ & $7(0.25-42)$ \\
$\begin{array}{l}\text { Previous hospitalization } \\
\quad(\%)\end{array}$ & $120(76)$ & $44(45)$ & $167(63)$ \\
$\begin{array}{l}\text { Previous surgery (\%) } \\
\text { History of oral steroid } \\
\quad \text { use (\%) }\end{array}$ & $73(46)$ & $17(18)$ & $91(35)$ \\
$\begin{array}{l}\text { History of intravenous } \\
\quad \text { steroid use (\%) }\end{array}$ & $76(48)$ & $72(74)$ & $208(79)$ \\
\hline
\end{tabular}

For some items, the numbers may not add up to the total number of subjects due to missing responses. *Includes eight patients who did not specify type of inflammatory bowel disease

TABLE 3

Characteristics of current users and nonusers of complementary medicine in the inflammatory bowel disease study population

\begin{tabular}{lccc}
\hline & $\begin{array}{c}\text { Current users } \\
(\mathbf{n = 8 8})\end{array}$ & $\begin{array}{c}\text { Current nonusers } \\
(\mathbf{n = 1 7 5 )}\end{array}$ & $\mathbf{P}$ \\
\hline Sex (\%) & & & \\
$\quad$ Male & $44(50)$ & $91(52)$ & \\
$\quad$ Female & $44(50)$ & $83(48)$ & 0.8 \\
Age, median (years) & 37 & 36 & 0.6 \\
Education (\%) & & & \\
$\quad$ Highschool or less & $12(14)$ & $31(18)$ & \\
$\quad$ Some postsecondary & $75(86)$ & $142(82)$ & 0.5 \\
Disease* (\%) & & & \\
$\quad$ Crohn's disease & $55(66)$ & $103(60)$ & \\
$\quad$ Ulcerative colitis & $28(34)$ & $69(40)$ & 0.3 \\
Disease activity* (\%) & & & \\
$\quad$ Active & $61(70)$ & $121(70)$ & \\
$\quad$ Inactive & $26(30)$ & $53(30)$ & 1.0 \\
Duration, median years & 7 & 7 & 0.8 \\
Previous surgery (\%) & $22(25)$ & $69(39)$ & 0.027 \\
Previous hospitalization (\%) & $50(56)$ & $117(67)$ & 0.1 \\
History of oral steroids (\%) & $61(69)$ & $147(84)$ & 0.01 \\
History of intravenous & $28(32)$ & $77(44)$ & 0.06 \\
$\quad$ steroids (\%) & & & \\
\hline
\end{tabular}

*Includes only those who specified type of inflammatory bowel disease

\section{RESULTS}

Responses were received from 275 people. Twelve responses were not included in the analysis because the respondents did not indicate whether they had used CAM or no disease information was provided, making it questionable whether they had IBD. Of the 263 eligible responses, 104 were completed during phase 1 and 159 were com- 
TABLE 4

Reasons for seeking complementary treatments for inflammatory bowel disease among those who had used it within the previous two years

\begin{tabular}{lc}
\hline $\begin{array}{l}\text { "I started to use alternative therapies because my } \\
\text { physicians..." }\end{array}$ & $\begin{array}{c}\text { Response } \\
\text { (\%) }\end{array}$ \\
\hline "Gave me treatments which did not help" & 57 \\
"Prescribed medications which have serious side effects" & 53 \\
"Think differently about causes and treatment of disease & 47 \\
$\quad$ than I do" & \\
"Spoke of my disease in terms that left me little, if any, \\
$\quad$ hope"
\end{tabular}

pleted during phase 2 . There were no significant differences in demographic or disease characteristics, or in the degree of use or satisfaction with CAM between respondents during phase 1 and phase 2 . Therefore, results are reported for the combined group. The demographic and disease characteristics of the study population are shown in Tables 1 and 2. The respondents were predominantly from the United States (63\%) and Canada (29\%), with only $9 \%$ from various other countries.

Forty-six per cent of respondents reported using some form of complementary therapy in the previous two years. Current use was reported by $34 \%$.

In the bivariate analysis, sex, age, education level, type of IBD, disease activity and duration were not predictive of current use of CAM (Table 3). Current users were less likely to have previously had any type of surgery for their IBD or received intravenous or oral steroids than nonusers; this was found in both those with ulcerative colitis and those with Crohn's disease, although the difference was statistically significant only in those with Crohn's disease. Respondents from elsewhere in the world were more likely to be using CAM (48\%) than those in the United States $(35 \%)$ or Canada $(27 \%)$, but this difference was not statistically significant. Multivariate analysis indicated that, of these factors, a history of never using oral steroids was the strongest predictor of CAM use (OR 2.3; 95\% CI 1.3 to 4.3 ).

Table 4 shows the reasons for seeking CAM. The most common reasons indicated were the perceived ineffectiveness of $(57 \%)$ or the side effects associated with $(53 \%)$ conventional medicine. However, a significant proportion of subjects also reported other reasons unrelated to previous conventional treatment. These included the belief that the respondents' physicians thought differently about causes and treatments of disease than did the patient $(47 \%)$.

The most common types of therapies reported by current users were vitamins $(63 \%)$, herbal products $(58 \%)$ and natural health practices $(44 \%)$. The most common herbs reported were aloe, slippery elm and ginseng. Among natural health practices, use of homeopathy was reported by $20 \%$ and traditional Chinese medicine by $13 \%$. Ten per cent were using the Gottschall carbohydrate specific diet. Most users employed multiple therapies. Eighty per cent of current users reported the use of more than one type of therapy and $52 \%$ the use of four or more therapies.

There were some differences, which did not reach statistical significance, in the types of therapies used by patients in different countries. Also, due to the small number of participants, these results should be interpreted cautiously. For example, the use of homeopathy was reported by $30 \%$ of Canadians, $19 \%$ of Americans and $9 \%$ of respondents from other countries. In contrast, the use of acupuncture or acupressure was reported by $15 \%$ of Canadians and Americans but by $36 \%$ of those from other countries.

Those who had used CAM were asked to rate their satisfaction with it on a five-point scale, with 1 being not at all satisfied and 5 being very satisfied. Thirty-two per cent reported their satisfaction as being at least a 4 . Those who were most likely to be satisfied to this degree were those who reported using CAM because they thought differently from their doctor about the causes and treatments of disease (OR 4.5; 95\% CI 1.9 to 10.6) or because their doctor had not taken into consideration their way of life (OR 3.0; $95 \%$ CI 1.3 or 7.1 ). The few patients who indicated that they used CAM because their doctor did not treat them were the least likely to be satisfied (OR $0.3 ; 95 \%$ CI 0.07 to 1.5), and those who sought CAM because they found conventional medicine unhelpful were also less likely to be satisfied, although these differences did not reach statistical significance (OR 0.8; CI 0.4 to 1.8 ).

Comparison with Calgary specialty clinic patients: In a previous study (7), 134 patients who had attended gastroenterology clinics in Calgary completed the same confidential, mailed questionnaire. Through a review of e-mail addresses given by respondents to the Internet survey, it was determined, to the best of the authors' knowledge, that no one completed both questionnaires. The clinic sample was quite different from the Internet sample. The Internet subjects tended to be better educated than the local subjects ( $83 \%$ with at least some postsecondary education compared with $64 \%$ of the local subjects). In addition, the Internet subjects had a shorter mean duration of disease (seven years versus 12 years) and were less likely to have previously undergone surgery ( $35 \%$ versus $58 \%$ ). A similar proportion in both groups had previously received oral and intravenous steroids.

The proportion of patients reporting previous or current use of CAM was quite similar in both groups. In the local survey, $51 \%$ and $33 \%$ reported previous or current 
use of CAM, respectively, versus $46 \%$ and $34 \%$ in the current study. However, there were important differences between the two studies in terms of the reasons and determinants of CAM use. The two most common reasons for using CAM were the same in both the local and Internet sample (side effects and lack of beneficial effect of conventional medicine). However, the Internet group reported seeking CAM because their doctor thought differently about causes and treatments of disease $(47 \%)$ and that their doctor did not give them the care or human touch that they needed $(31 \%)$ much more commonly than the local sample ( $21 \%$ and $12 \%$, respectively).

The other major difference between the present Internet study and the earlier clinic study was in the determinants of CAM use. In the earlier study, factors associated with a worse disease course (use of intravenous or oral steroids and previous hospitalization or surgery) were associated with a higher likelihood of using CAM. In marked contrast, in the Internet sample, these factors were associated with a lower likelihood of using CAM.

Forty-one per cent of the clinic patients rated their satisfaction with CAM with a score of at least a 4 out of 5 (unpublished data). This is slightly higher than the $32 \%$ who reported this level of satisfaction in the present study.

\section{DISCUSSION}

In keeping with other single-centre studies, we have shown that the use of CAM by patients with IBD is common. The proportions of patients who had used or were currently using CAM were very similar to the proportions found in our earlier study of IBD patients in Calgary (7). Also in keeping with our previous study was the common use of multiple different types of CAM. However, there were also important differences between the two studies. The Internet group reported seeking CAM because their doctor thought differently about causes and treatments of disease, and because their doctor did not give them the care or human touch that they needed much more frequently than our local sample. Persons indicating these reasons may be less comfortable within the framework of conventional medicine.

Patients who stated that they had used CAM because they thought differently from their doctor about diseases and their treatments were more likely to be satisfied. In contrast, those who had sought CAM after conventional medicine had failed them were less likely to be satisfied. This suggests that health attitudes and beliefs are an important determinant of satisfaction with CAM.

Only about a third of users rated their satisfaction with their experiences with CAM as at least a 4 out of 5 . Because patients often used more than one therapy concurrently, it was not possible to determine which individual therapies were viewed most favourably.

Another major difference between this study and our previous study concerns the determinants of CAM use. In our previous study, factors associated with a worse disease course (use of intravenous or oral steroids and previous hospitalization or surgery) were associated with a higher likelihood of using CAM. In marked contrast, these factors were associated with a lower likelihood of using CAM in the Internet sample.

These observations suggest that there were substantive differences between the population surveyed on the Internet and those surveyed locally, in terms of both their disease severity and their health beliefs. It is likely that a larger proportion of IBD patients recruited through the Internet were less comfortable within the framework of conventional medicine. In addition, this sample included more people who had less severe disease as measured by corticosteroid use and previous surgery. This less sick population may be less likely to see a gastroenterologist and, therefore, may not be represented in a clinic-derived sample. It is important to emphasize that neither of these differences resulted in a substantial difference in the overall proportion of subjects using CAM between the two studies. Clearly, from a cross-sectional study, it is inappropriate to propose causal associations about CAM use and disease severity.

By using the Internet, we were able to recruit a large number of subjects with little effort. The subjects were predominantly from the United States, but a significant proportion were from other countries. The sample was heterogeneous, including a range of disease severity, disease duration and treatments. However, this study was limited by the inherent difficulties in conducting a study on the Internet, which have been discussed elsewhere in terms of IBD research $(9,10)$. These difficulties include the inability to sample a defined population or to even determine exactly what population was sampled. Not all people have access to the Internet. In a recent study on the information needs and sources of patients with IBD, 33\% reported having access to the Internet, although only $23 \%$ had used it to get information about their disease (8). Those using the Internet are likely more educated and may have a higher socioeconomic status than Internet nonusers. Higher education has been associated with CAM use (1). Because many participants of the Internet sample found the questionnaire through actively seeking IBDrelated Internet sites, they are likely characterized by a strong desire for knowledge about their disease, and to be in control of their disease and its management. One might suspect that those who took the time to access the website and complete the questionnaire were those who had the most favourable experiences with and opinions about CAM. However, this may not have been the case because only a third of subjects rated their satisfaction as at least a 4 out of 5 , and the clinic subjects overall appeared to be more satisfied with CAM than the Internet subjects.

Soetikno et al (11), in a study of quality of life of patients with ulcerative colitis following surgery, also found systematic differences between a clinic and an Internet population. However, in contrast to our study, the ulcerative colitis patients recruited through the Internet were more ill than those recruited through the clinic. This dif- 
ference may be explained by the different focuses of the studies. A study of quality of life might be expected to attract those whose quality of life has been adversely affected by more serious disease, whereas disease activity may not have influenced the likelihood of responding to this survey, although other selection pressures may have occurred.

A second limitation of this study is that there was no way to determine whether respondents had confirmed IBD or among the anonymous respondents whether individuals completed the questionnaire more than once. At least one questionnaire was completed by the mother of a young child with IBD. It is possible that more surrogates completed questionnaires. Possibly the greatest threat to the validity of the findings of this study would be if a significant proportion of respondents did not have IBD but another disorder, such as irritable bowel syndrome. Because irritable bowel syndrome patients are unlikely to receive steroids or undergo surgery, and in previous studies were more likely to use CAM (4), inclusion of a significant proportion of these patients would have biased the results in the direction seen here.

A final limitation is the inability to validate the data provided by the subjects about their disease and treatment. However, this limitation exists for any survey that uses a self-report questionnaire. One advantage of using the Internet is that respondents may be less hesitant to say something negative about their physicians than those recruited through the clinic.

Despite the limitations in conducting research using the Internet, this study suggests that studies that sample specific IBD populations can come up with quite different re- sults in terms of the determinants of and reasons for CAM use. Studies based on samples from tertiary care centres or any specific population not representative of the general IBD population may provide a limited view of many important features of CAM use by these patients. With a sample drawn from a tertiary care centre, this limited view would reflect the severity of illness of the patients in this setting and that they may be more comfortable within a conventional medicine framework. Therefore, a more comprehensive study of IBD patients is required to truly understand the important issues surrounding the use of CAM in this population. In addition, this study demonstrates the potential usefulness of using the Internet to collect data as long as its limitations are understood. It is an efficient method of recruiting subjects and collecting data for exploratory studies that do not rely on a representative random sample. Findings from such an exploratory study could then form the basis for a more rigorous study.

ACKNOWLEDGEMENTS: Dr Hilsden is supported by a fellowship from the Medical Research Council of Canada.

\section{REFERENCES}

1. Astin JA. Why patients use alternative medicine - Results of a national study. JAMA 1998;279:1548-53.

2. Aakster CW. Concepts in alternative medicine. Soc Sci Med 1986;22:265-73.

3. Northcott HC. Alternative health care in Canada. In: Bolaria BS, Dickinson HD, eds. Health, Illness, and Health Care in Canada. Toronto: Harcourt, Brace \& Co, 1994:487-503.

4. Smart HL, Mayberry JF, Atkinson M. Alternative medicine consultations and remedies in patients with the irritable bowel syndrome. Gut 1986;27:826-8.

5. Verhoef MJ, Sutherland LR. Outpatient health care utilization of patients with inflammatory bowel disease. Dig Dis Sci 1990;35:1276-80.

6. Moser G, Tillinger W, Sachs G, et al. Relationship between the use of unconventional therapies and disease-related concerns: a study of patients with inflammatory bowel disease. J Psychosom Res 1996;40:503-9.

7. Hilsden RJ, Scott CM, Verhoef MJ. Complementary medicine use by patients with inflammatory bowel disease. Am J Gastroenterol 1998;93:697-701.

8. Hilsden RJ, Dunn C, Patten S, Scott CM, Verhoef MJ. Information needs and seeking behaviors of patients with inflammatory bowel disease. Gastroenterology 1998;114:A995. (Abst)

9. Hilsden RJ, Scott CM, Verhoef MJ. Research and the Internet. Am J Gastroenterol 1998;93:484-5. (Lett)

10. Soetikno RM, Lenert LA, Provenzale D. Research and the Internet - Response. Am J Gastroenterol 1998;93:485. (Lett)

11. Soetikno RM, Mrad R, Pao V, Lenert LA. Quality-of-life research on the Internet: feasibility and potential biases in patients with ulcerative colitis. J Am Med Inform Assoc 1997;4:426-35. 


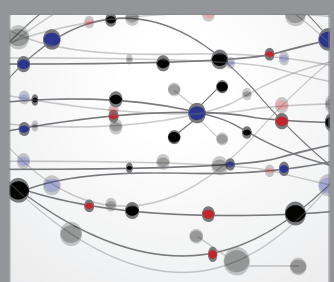

The Scientific World Journal
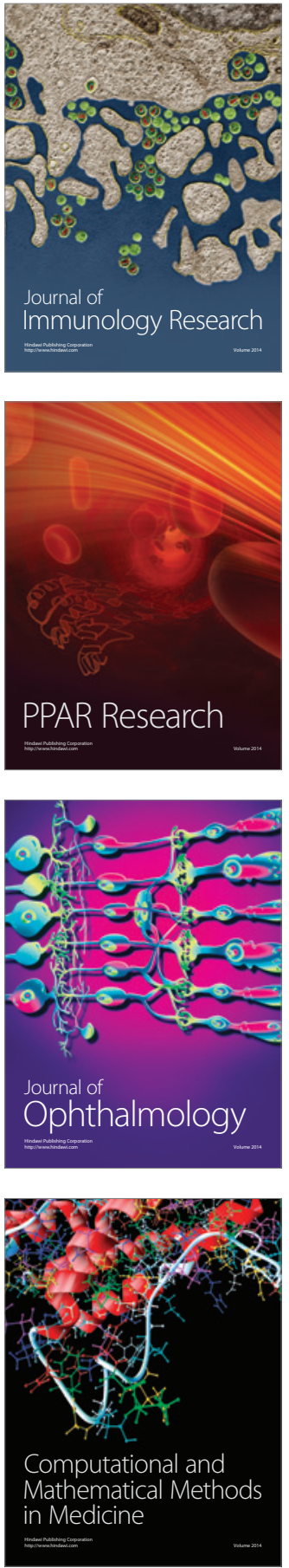

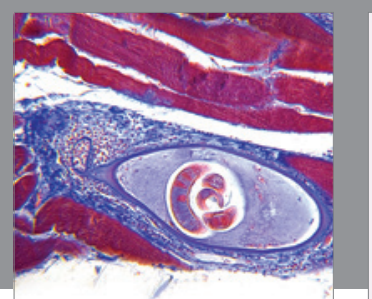

Gastroenterology Research and Practice

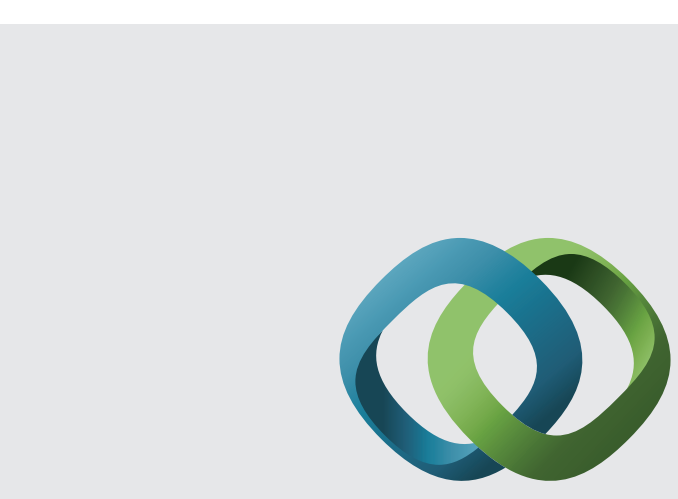

\section{Hindawi}

Submit your manuscripts at

http://www.hindawi.com
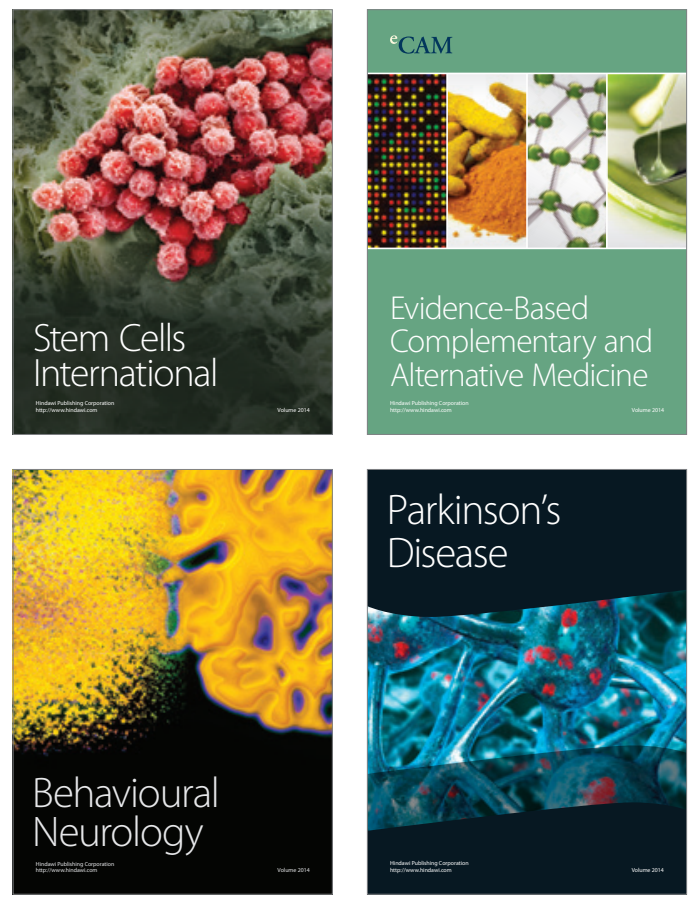
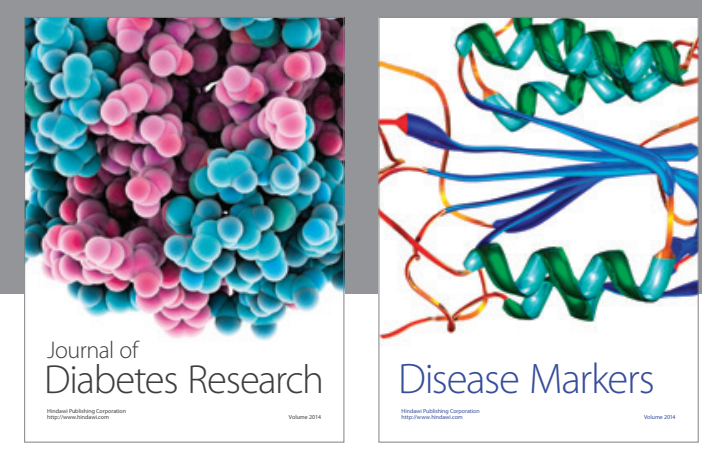

Disease Markers
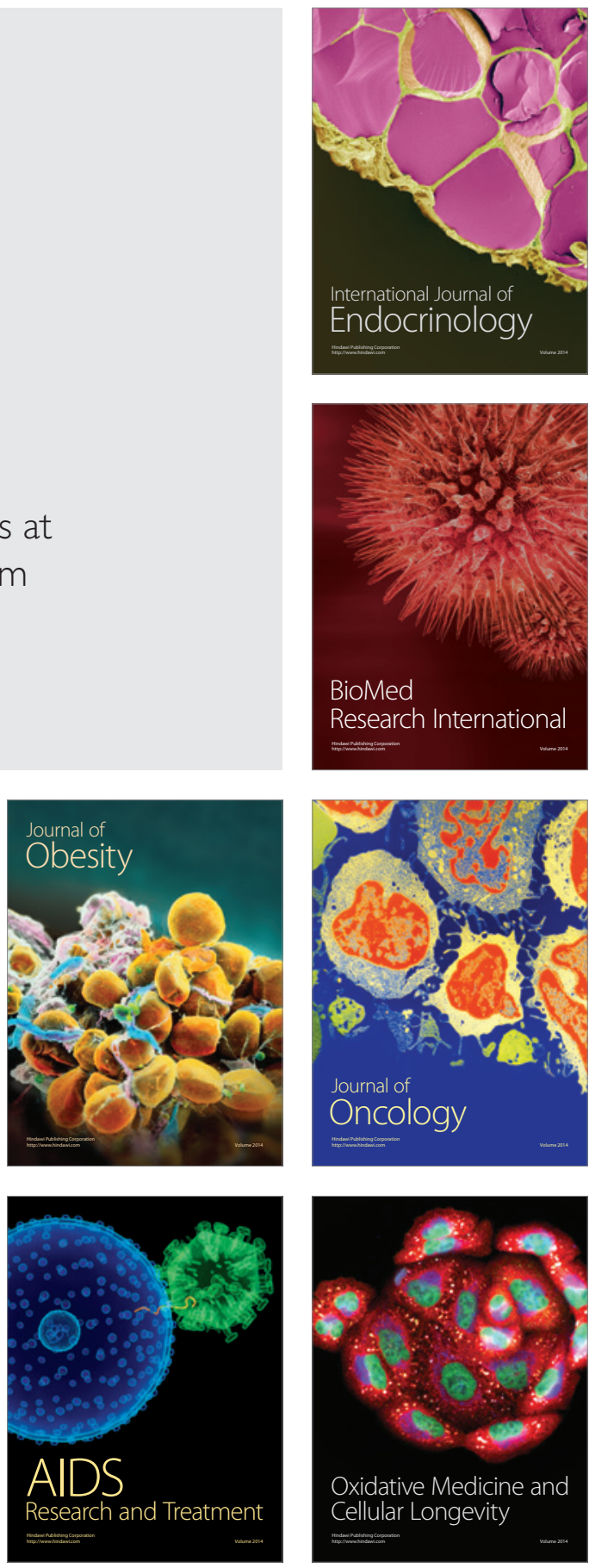